\title{
LOWER EXTREMITY FRACTURES IN PATIENTS WITH SPINAL CORD INJURY
}

\author{
By Alvin A. Freehafer, M.D., Coletta M. Hazel, R.N. and Connie L. Becker, R.N. \\ From the Departments of Orthopaedics, Highland View Hospital and Case Western Reserve \\ University School of Medicine, Cleveland, Ohio, U.S.A.
}

\begin{abstract}
Lower limb fractures occurring in patients with established spinal paralysis were considered different enough to warrant variations in treatment usually provided to patients without paralysis. Treatment should ensure that the functional level will be unchanged after healing occurs. Splints made of soft materials were effective, inexpensive, safe, and allowed for good healing with early rehabilitation.
\end{abstract}

Key words: Spinal cord injury; Lower extremity fractures; Soft splints.

THE RESULTS of a study from this institution on fractures of long bones in patients with spinal cord injury were published by Freehafer and Mast (I965). Fractures occurring at the time of the spinal cord injury were not studied. The major published works on this subject clearly point out the problems that are encountered in treating fractures that occur late after spinal cord injury (Katz, I953; Comarr et al., 1962; Eichenholtz, I963; Freehafer \& Mast, I965; Meinecke et al., I967; McMaster \& Stauffer, 1975). Patients with spinal paralysis have physiological, metabolic, functional, social and psychological characteristics and needs that differ drastically from those without paralysis. It becomes mandatory, therefore, to vary the treatment for the paralysed patient rather than to give the same treatments usually provided for the average patient without paralysis.

Certain observations were made from our study in 1965 which formed the basis of subsequent treatment from which data for this study were gathered. From this experience the following impressions and recommendations have evolved:

I. The functional level should be unchanged after fracture healing.

2. Healing of fractures should take place with minimum risk of complications.

3. Non-operative treatment of fractures was recommended as the method leading to the most rapid union, the least number of complications, the quickest rehabilitation and the smallest morbidity rate.

4. Patients should be out of bed in wheelchairs as soon as possible or within the first few days after fracture.

5. Traction was rarely indicated.

6. Plaster casts and splints or any hard materials used for immobilisation were potentially dangerous and should be avoided.

7. Open reduction was rarely necessary. Occasionally uncontrollable spasticity could cause protrusion of bone fragments through the skin necessitating open reduction or simple removal of bony prominences.

8. Shortening and angulation of healed fractures were acceptable in sitters, but rotational deformity in a sitter was unacceptable.

9. Patients who walked should be treated by conventional methods which give an anatomical result permitting the patient to resume walking at the same functional level. 
IO. Bone in patients with spinal paralysis was atrophic often making internal fixation unsatisfactory.

II. Pillow splints were recommended in most fractures occurring in the lower extremities.

The purpose of this communication was to study further the problems of fractures which occurred after spinal cord injury (not at the time of spinal cord injury) in order to review the principles of care, and to make recommendations for optimum treatment in the future.

\section{Materials and Methods}

All of the patients included in this study had a spinal cord injury. They were under observation at Highland View Hospital since 1963 when a spinal injury service was formed. During this time 546 patients were treated. None of the patients was included in the original study published in 1965 .

Since I963 I8 patients with spinal paralysis with a total of 27 fractures of the lower extremities received treatment, based on our previous experience. There were 546 patients in our programme which represented an incidence of 3 per cent. This experience was added on to our study of 1965 (Freehafer \& Mast, I965) which included 23 patients with 46 fractures reviewed back to I947. This is a total experience of $4 \mathrm{I}$ patients and 73 fractures during the past 32 years.

The causes of spinal paralysis in this series were nine automobile accidents, three falls, one diving accident, one gunshot wound, one surgical removal of benign spinal cord tumour, one correction of a congenital scoliosis, one instability of occiput, $\mathrm{C}_{1}$ and $\mathrm{C}_{2}$ in rheumatoid arthritis, and one transverse myelitis.

The fractures in this series were caused by relatively minor injuries. Eleven occurred at the time patients were transferring and three fractures occurred when patients were turned in bed. There was no recollection of any injury on six occasions. Three fractures occurred in the vicinity of a pressure sore. One patient sustained three fractures which probably occurred because his activities were too strenuous for someone with complete absence of sensation and muscle control. One patient was wheeling through the woods when his foot struck a tree, twisting his leg and causing a tibial fracture.

The fractures were distributed diffusely throughout the lower limb. In the femur there were four through the neck, three through the trochanter, five in the proximal femur, four in the shaft, and five in the supracondylar region (Fig. I). In the tibia there were two fractures proximally, one in the shaft, and three distally. While I3 patients had only one fracture, one had five fractures, one had three fractures, and three had two fractures.

\section{Treatment and Results}

Soft bulky splints were used most frequently in treating the fractures of the long bones of the lower limbs. They were inexpensive, effective, safe, and led to satisfactory results. They allowed the patients to be functional and out of bed.

While pillows were used frequently and described in detail in our report of I965, many modifications and varieties of soft splints were used since then. A pillow or pillows were sometimes secured to the lower limb around the fracture. These have been described in detail (Freehafer \& Mast, 1965; McMaster \& Stauffer, 1975). Sometimes (especially for proximal femoral fractures) the lower extremities were fixed to a pillow placed between the thighs. A blanket was often 

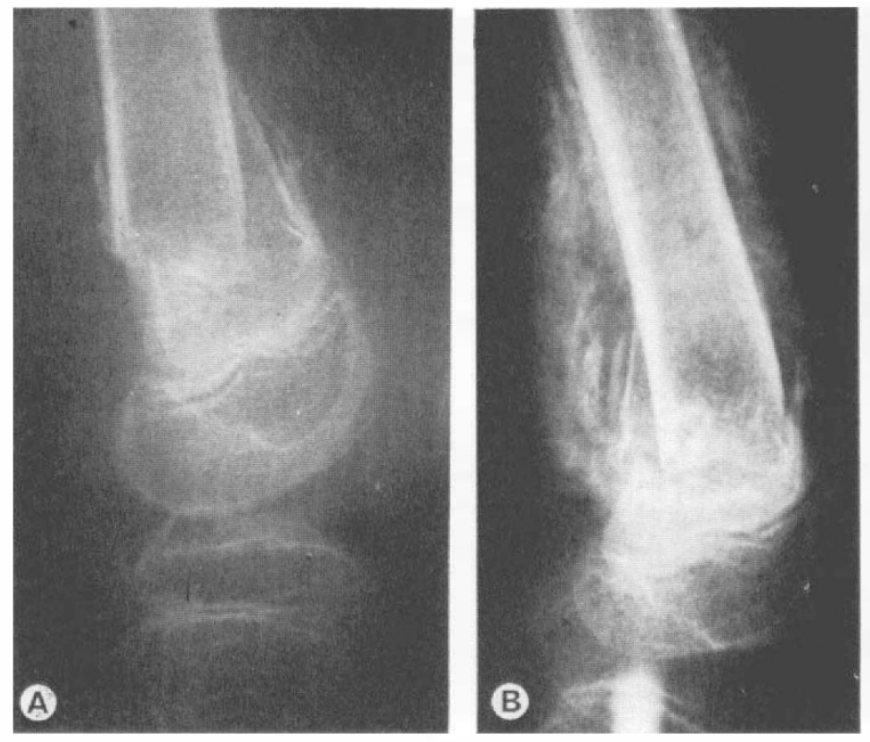

FIG. I

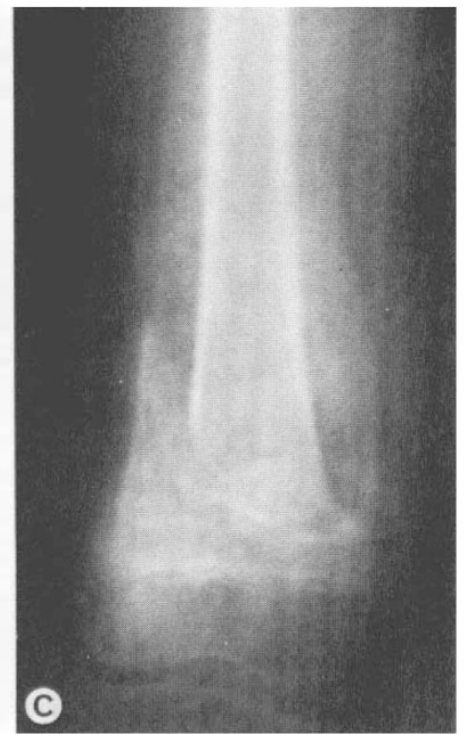

A, A I2-year-old boy with an acute supracondylar fracture of the right femur. B and C, Appearance of fracture after 2 weeks. Treatment consisted of soft splint, bed rest for 2 days and early mobilisation.

wrapped around the fracture site and fixed with adhesive tape or elastic bandage, or stockinette (Fig. 2). Occasionally Webril was wrapped around the fractured limb and covered with elastic bandages to form a bulky soft splint, limiting motion at the fracture site. While plaster was usually avoided, in a few cases plaster casts were applied but over abundant Webril or cotton batting and with no attempt to apply moulding or pressure. Plaster splints or splints made of hard materials were not used following our published study in I965.

The main advantage of soft splints, no matter what soft material was used, was that the patient could be out of bed and up in a chair soon after the fracture occurred.

There were some patients, however, who became ill after the fracture occurred so that bed rest was often necessary for two to five days. Temperature elevation, chills, malaise, nausea and swelling of the fractured extremity were the most common presenting symptoms. Because of the absence of sensation pain was rarely a complaint.

Shortening or angulation occurred rarely. Rotational deformity did not occur. In order to prevent rotational deformity the patient should sit with the lower limbs flexed and the feet properly positioned on foot rests and in the normal sitting position.

Hospitalisation was occasionally necessary for severe swelling, temperature elevation, and malaise which often resolved by five days. Several patients had pressure sores which required hospitalisation. In these cases pressure sores in the region of the fracture probably contributed to the break.

Femoral neck fractures were left untreated if complete paralysis was present. They were asymptomatic and caused no problem sitting, transferring or gaining independence later. One patient with incomplete paralysis was a community walker aged 6I and a Moore prosthesis was used satisfactorily. 


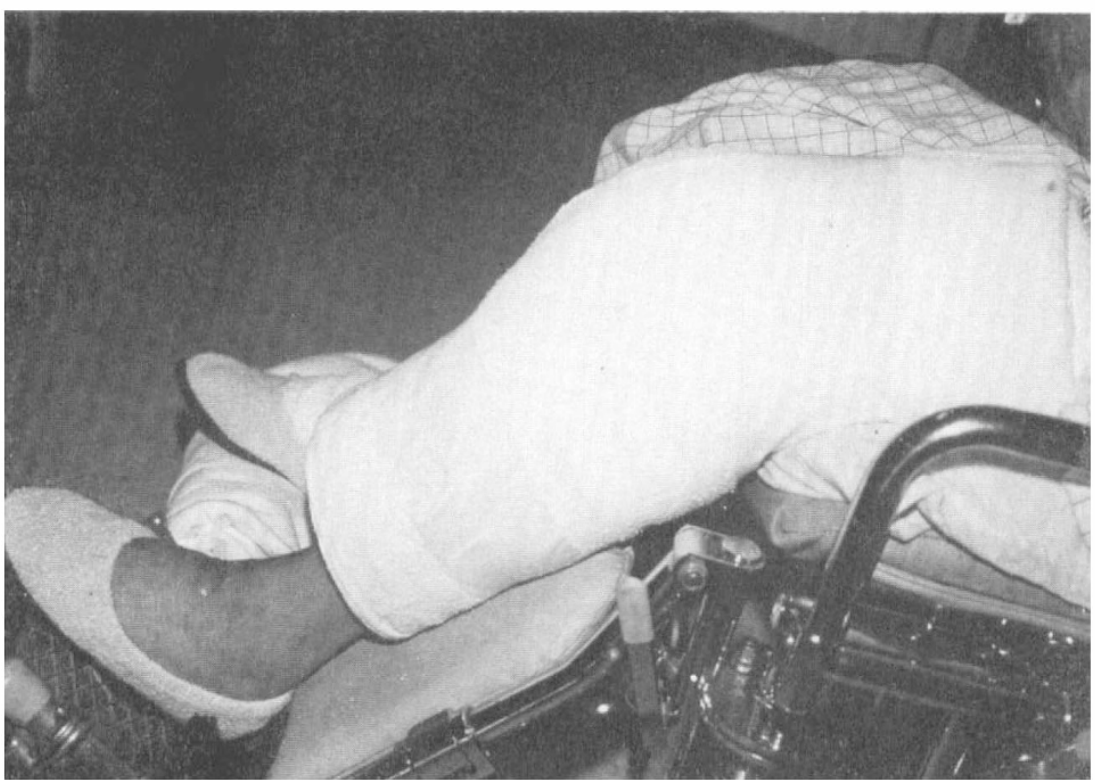

FIG. 2

This shows a soft splint made of a bath blanket wrapped around a supracondylar fracture and held in place with adhesive tape.

Intertrochanteric fractures in the paralysed patient did not receive operative fixation. They all healed and the use of a pillow between the thighs was helpful in getting the patient up in the wheelchair. The three fractures in this series progressed to union without any treatment.

Fractures of the proximal femur were probably the most difficult to manage and angulation frequently occurred in this region (Fig. 3, a and b). Internal
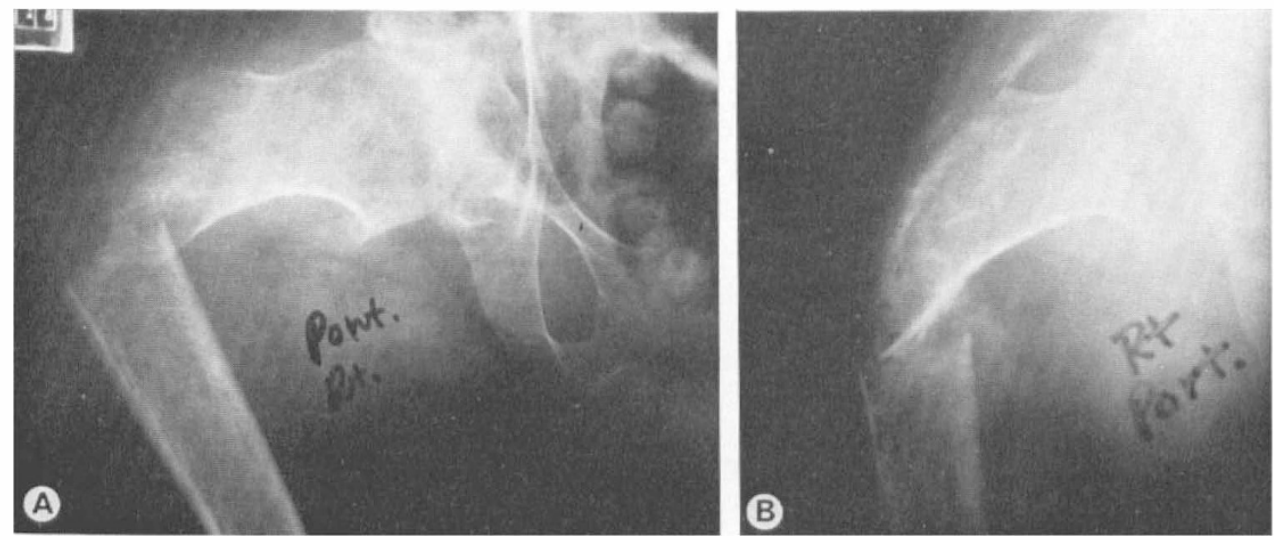

FIG. 3

A, Case I8, A 30-year-old patient with complete paralysis below C-6. He sustained this fracture about 2 weeks after surgical treatment of a pressure sore over the right trochanter. $\mathrm{B}$, The roentgenographic appearance 2 weeks later. The fracture was clinically solid at this time. He was treated on a turning frame with tibial pin traction for 3 weeks and then allowed up in a chair. 
fixation of these fractures should be considered if shortening or angulation will result in unacceptable functional or cosmetic results. One patient had a sharp spike of bone which protruded through the skin because of flexor spasms. She also had a large trochanteric pressure sore which probably contributed to the fracture. The spike (about five centimetres below the trochanter) was easily removed with a rongeur without anaesthesia. She was treated on a turning frame because of the pressure sore, a tibial pin traction was applied, and healing took place after 2 months. One patient was unusual because he had an ankylosed hip from heterotopic bone, but healing occurred promptly although it was hoped that non-union would occur.

\section{Discussion}

Major problems encountered in the past in treating lower extremity fractures in patients with spinal cord injury have included osteomyelitis, pressure sores, urinary infections and calculi, respiratory infections and contractures. A review of the literature on fractures of the lower extremities in patients with spinal cord injury documents the occurrence of these complications and others (Comarr et al., I962; Eichenholtz, 1963; Freehafer \& Mast, 1965). Our review in 1965 and our interest in this problem have guided us to treat fractures of the lower limbs in most instances without operation. No important complications occurred in this series.

The bones of the lower limbs in patients with spinal cord injury become atrophic and fractures are largely pathological. Loss of sensation and muscle control make the patient more susceptible to injury. In the present series one gets the impression that both patients and those who care for them have been a little careless in turning and transferring, unaware of the possibility of sustaining fractures with minimum injury.

Ideally patients with spinal cord injury should be treated in a centre where knowledge and experience for this group of patients have been developed. Paralysed patients with fractures of the long bones of the lower limbs present many problems. Treatment for this group of patients is different from non-paralysed patients and referral to, or consultation with, a spinal cord centre or those knowledgeable in this field is recommended.

The recommendations of fracture care developed from our study published in I 965 formed the basis of treatment in most of the patients in this present series. Treatment should provide for fracture healing with a minimum of danger to the patient, should cause little or no interference with the patient's daily routine, and should lead to a functional level that is unchanged from the pre-fracture status.

\section{SUMMARY}

This study was conducted on I8 patients with 27 fractures from I963 to the present. Fractures that occurred at the time of onset of spinal paralysis were not included in this study.

Patients with established paralysis from spinal injury have physiological, functional, social and psychological characteristics and needs that differ drastically from those without paralysis. It is often necessary to vary the treatment for the paralysed patient rather than to give the same treatments usually reserved for the average patient without paralysis.

Non-operative treatment usually consisted of splints made from soft materials (soft splints). These were effective, inexpensive, safe, and allowed for good healing with early rehabilitation. 
Treatment should ensure that the functional level will be unchanged after healing occurs.

\section{RÉSUMÉ}

Cette étude porte sur dix-huit patients qui, de I963 jusqu'au présent, ont été acteints de vingt-sept fractures. Elle ne contient pas de cas de fractures apparues au moment de la paralysie dorsale.

Les patients atteints d'une paralysie permanente dûe à une lésion dorsale présentent des caractéristiques physiologiques, fonctionnelles, sociales et psychologiques ainsi que cies besoins qui diffèrent tous radicalement de ceux des patients non-paralysés. Dans le cas d'un patient paralysé, il est souvent nécessaire de varier le traitement plutôt que de lui administrer les traitements généralement réservés au patient typique non-paralysé.

Le traitement non-opératoire consiste généralement en attelles faites d'un matériau souple (Attelles Souples). Celles-ci se sont révélées efficaces, peu coûteuses, sans risque et ont permis une bonne cicatrisation avec réhabilitation précoce.

Le traitement devrait assurer que le niveau fonctionnel demeure inchangé après cicatrisation.

\section{ZUSAMMENFASSUNG}

Diese Untersuchung wurde an achtzehn Patienten mit siebenundzwanzig Knochenbrüchen von I963 bis zum jetzigen Zeitpunkt angestellt. Knochenbrüche, die zum Zeitpunkt der einsetzenden Rückgratslähmung passierten, sind in dieser Untersuchung nicht eingeschlossen.

Patienten mit einer feststehenden, von einer Rückgratsverletzung herrührenden Lähmung haben physiologische, funktionelle soziale und psychologische Eigenschaften und Bedürfnisse, die von denen der Patienten ohne Lähmung drastisch abweichen. Es ist oft notwendig, die Behandlung des gelähmten Patienten anders zu gestalten und ihm nicht die gleiche Behandlung zukommen zu lassen, wie sie der normale Patient ohne Lähmung erhält.

Eine Behandlung ohne Operation bestand gewöhnlich darin, den Bruch mit weichen Materialien zu schienen (weiche Schienen). Dies war wirksam, nicht teuer und sicher und machte eine schnelle Heilung mit früher Rehabilitierung möglich.

Die Behandlung sollte sicherstellen, daß die Funktionsstufe nach vollendeter Heilung unverändert ist.

\section{REFERENCES}

Comarr, A. E., Hutchinson, R. H. \& Bors, E. (1962). Extremity fractures of patients with spinal cord injuries. Am. F. Surg., 103, 732-739.

EichenHOLTZ, S. N. (I963). Management of long-bone fractures in paraplegic patients. F. Bone and foint Surg., 45A, 299-310.

FREEHAFER, A. A. \& MAST, W. A. (I 965 ). Lower extremity fractures in patients with spinal cord injury. F. Bone and foint Surg., 47A, 683-694.

KaTz, J. F. (1953). Spontaneous fractures in paraplegic children. F. Bone and foint Surg., 35A, 220-226.

MCMASTER, W. C. \& STAuffer, E. S. (1975). The management of long bone fracture in the spinal cord injured patient. Clin. Orthop., I12, 44-52.

Meinecke, F. W., RehN, J. \& Leitz, G. (I967). Conservative and operative treatment of fractures of the limbs in paraplegia. In Proceedings of the Sixteenth VA Annual Clinical Spinal Cord Injury Conference, I7, 77-91. 